\title{
Iron/Iron Oxide Nanoparticle Sequestration of Catalytic Metal Impurities from Aqueous Media and Organic Reaction Products.
}

\author{
Janet E. Macdonald, Joel A. Kelly, Jonathan G. C. Veinot
}

\section{Experimental Section}

\section{Reagents}

Iron (III) chloride hydrate, copper sulfate and styrene were purchased from Fisher, cobalt (II) nitrate from Mallinckrodt, silver nitrate from Englehard, sodium borohydride from EMD Chemicals, sodium nitrate from ACP chemicals, rhodium (III) chloride hydrate from Colonial Metals and potassium nitrate from BDH Chemicals. The remaining reagents were purchased from Sigma-Aldrich. All reagents were used as received without further purification. Phenyl azide was synthesized using a literature procedure. ${ }^{1}$ Typically, in-house deionized water was employed for the synthesis of iron nanoparticles. Sequestration studies were performed using $18.2 \mathrm{M} \Omega \mathrm{cm}$ water.

Synthesis of $\mathrm{Fe}_{\mathrm{x}} \mathrm{O}_{\mathrm{y}} @ \mathrm{Fe}$

$\mathrm{Fe}_{\mathrm{x}} \mathrm{O}_{\mathrm{y}} @ \mathrm{Fe}$ were prepared using a modified literature procedure. ${ }^{2,3}$ Briefly, $\mathrm{FeCl}_{3} 6 \mathrm{H}_{2} \mathrm{O}$ $(5.70 \mathrm{~g}, 21 \mathrm{mmol})$ was dissolved in $400 \mathrm{~mL}$ of deionized water. A solution of $\mathrm{NaBH}_{4}$ $(2.24 \mathrm{~g}, 59 \mathrm{mmol})$ in $30 \mathrm{~mL}$ of water was added dropwise while the iron chloride solution was stirred vigorously. The orange solution became dark with a black precipitate. The precipitate was vacuum filtered and washed with $500 \mathrm{~mL}$ of water followed by $50 \mathrm{~mL}$ of $95 \%$ ethanol. The resulting black paste was transferred to a round bottom flask and dried in vaccuo for two days to yield a black powder that was stored in an argon-filled glovebox $\left(<0.1\right.$ ppm $\left.\mathrm{H}_{2} \mathrm{O}, 0.6 \mathrm{ppm} \mathrm{O}_{2}\right)$. Yield: $1.06 \mathrm{~g}$.

Sequestration of Aqueous Metal Ions

Metal salt solutions (i.e., nitrates, chlorides, or acetates) were prepared at metal concentrations of $\sim 100 \mathrm{ppm}$ in $3 \times 10^{-6} \mathrm{M} \mathrm{KOH}$ solution. Silver nitrate, ruthenium chloride and rhodium chloride solutions were prepared in $18.2 \mathrm{M} \Omega \mathrm{cm}$ water. $\mathrm{Fe}_{\mathrm{x}} \mathrm{O}_{\mathrm{y}} @ \mathrm{Fe}$ were placed in round bottom flasks in an argon-filled glovebox and transferred to a Schlenk line. An appropriate metal ion solution was transferred to the flask to achieve a ratio of $50 \mathrm{mg}$ of $\mathrm{Fe}_{\mathrm{x}} \mathrm{O}_{\mathrm{y}} @ \mathrm{Fe}$ for every $10.00 \mathrm{~mL}$ of solution. The particle/solution mixture was subsequently capped and stirred for 30 minutes. The mixtures were allowed to settle for 2 minutes to allow the majority of the $\mathrm{Fe}_{\mathrm{x}} \mathrm{O}_{\mathrm{y}} @ \mathrm{Fe}$ to collect on the magnetic stir bar. This aided the subsequent gravity filtration in which remaining solids were removed. The addition of $\mathrm{KNO}_{3}(0.10 \mathrm{~g})$ and a second filtration was required to remove highly charged, dispersed particles. The resulting colorless filtrates were acidified with 
two drops of concentrated nitric acid to facilitate analysis of metal concentrations by Quadropole-Inductively Coupled Plasma-Mass Spectroscopy (Quad-ICP-MS).

\section{“Click” Cu(I) Catalyzed Cycloaddition ${ }^{4}$}

Phenylazide (0.59 g, $5 \mathrm{mmol})$ and 3-phenyl-1-propyne $(0.4 \mathrm{~mL}, 3 \mathrm{mmol})$ were suspended in $20 \mathrm{ml}$ of a 1:1 mixture of water:butanol. To this suspension, $0.5 \mathrm{~mL}$ of a freshly prepared 1.0 M sodium ascorbate solution was added followed by copper sulfate hydrate $(12.5 \mathrm{mg}, 0.05 \mathrm{mmol})$. The reaction mixture was stirred for 16 hours, until an off-white solid formed. The solid was filtered and washed twice with cold deionized water, yielding $715 \mathrm{mg}(94 \%) .{ }^{1} \mathrm{H} \mathrm{NMR}\left(400 \mathrm{MHz}, \mathrm{CDCl}_{3}\right): \delta 7.62(2 \mathrm{H}, \mathrm{m}), 7.53(1 \mathrm{H}, \mathrm{s}), 7.43$ $(2 \mathrm{H}, \mathrm{m}), 7.34(1 \mathrm{H}, \mathrm{tt}), 7.27(4 \mathrm{H}, \mathrm{m}), 7.20(1 \mathrm{H}, \mathrm{m}), 4.06(2 \mathrm{H}, \mathrm{s})$. The product was also confirmed to be 1,4-disubstituted 1,2,3 triazole by Gas Chromatography-Mass Spectroscopy (GC-MS).

Sequestration of $\mathrm{Cu}$ impurities from "Click" Cycloaddition Product

$129.2 \mathrm{mg}$ of the products from the aforementioned "Click" reaction were dissolved in 20 $\mathrm{mL}$ of THF and $0.5 \mathrm{~mL}$ of $\mathrm{KOH}$ solution (pH 10.3). This was added to $100 \mathrm{mg}$ of $\mathrm{Fe}_{\mathrm{x}} \mathrm{O}_{\mathrm{y}} @ \mathrm{Fe}$ and stirred for $3 \mathrm{~h}$ in oxygen free conditions. The mixture was allowed to stand for 2 minutes allowing for most of the nanoparticle powder to collect on the magnetic stir bar. Remaining solids were removed by gravity filtration and the iron nanoparticles were washed three times with THF. Approximately $2 / 3$ of the filtrate was added to $50 \mathrm{mg}$ of $\mathrm{Fe}_{\mathrm{x}} \mathrm{O}_{\mathrm{y}} @ \mathrm{Fe}$ and $0.5 \mathrm{~mL}$ of $\mathrm{KOH}$ solution $(\mathrm{pH} \mathrm{10.3)} \mathrm{and} \mathrm{stirred} \mathrm{for} 3 \mathrm{~h}$. The mixture was allowed to stand for 2 minutes allowing for most of the nanoparticle powder to collect on the magnetic stir bar. Remaining solids were removed by gravity filtration and the iron nanoparticles were washed three times with THF. Solvent from the two filtrates was removed in vaccuo yielding slightly yellow crystals (100\% of cycloadduct recovered). No additional products were observed by GC-MS.

\section{Determination of Metal Concentrations in "Click" Cycloaddition Product}

The organic product (ca. $50-85 \mathrm{mg}$ ) of was placed in a porcelain crucible and heated to $625{ }^{\circ} \mathrm{C}$ overnight in air. The remaining dark solids were dissolved in concentrated nitric acid, diluted with $18.2 \mathrm{M} \Omega \mathrm{cm}$ water in a $10.00 \mathrm{~mL}$ volumetric flask and metal concentrations were determined using Quad-ICP-MS.

Another approach involved dissolving the organic product (ca. 55-185 mg) in $8 \mathrm{M} \mathrm{HNO}_{3}$ ( $25.00 \mathrm{~mL}$ ), followed by analysis by Quad-ICP-MS for $\mathrm{Cu}$ content.

Synthesis of N,N-dimethyl- $\beta$-alanine hydrochloride ${ }^{5}$

$\beta$ - alanine (3.59 g, $40.3 \mathrm{mmol})$, formalin $(5 \mathrm{~mL})$ and $90 \%$ formic acid $(25 \mathrm{~mL})$ were refluxed for $8 \mathrm{~h}$. Concentrated $\mathrm{HCl}(5 \mathrm{~mL})$ was added and the solvent was removed in 
vaccuo giving a slightly yellow solid. Formic acid $(\sim 15 \mathrm{~mL})$ was added and the slurry was vacuum filtered and washed with formic acid. White solid $3.1 \mathrm{~g}, 55 \%$ yield. ${ }^{1} \mathrm{H}$ NMR (500 MHz, $\left.\mathrm{CDCl}_{3}\right): \delta 2.87-2.901(8 \mathrm{H}, \mathrm{m}), 3.41-3.437(2 \mathrm{H}, \mathrm{t})$.

Pd Catalyzed Heck Coupling 5

Bromobenzene $(1.05 \mathrm{~mL}, 10 \mathrm{mmol})$, styrene $(1.75 \mathrm{~mL}, 15 \mathrm{mmol})$, palladium acetate (16.3 mg, $72.6 \mu \mathrm{mol}), \mathrm{N}, \mathrm{N}$-dimethyl- $\beta$-alanine hydrochloride $(10 \mathrm{mg}, 71.6 \mu \mathrm{mol})$, potassium carbonate $(2.72 \mathrm{~g}, 20 \mathrm{mmol})$ and anhydrous dimethyformamide $(10 \mathrm{~mL})$ were stirred and heated to $130{ }^{\circ} \mathrm{C}$ for $16 \mathrm{~h}$ leaving a dark solution. The product was extracted in diethyl ether and washed with water three times. The ether layer was gravity filtered to remove any black precipitate and the solvent was removed in vaccuo. Slightly yellow crystals, $1.77 \mathrm{~g}$ of trans-stilbene. Yield $98 \%{ }^{1} \mathrm{H}$ NMR $\left(400 \mathrm{MHz}, \mathrm{CDCl}_{3}\right): \delta 7.50(4 \mathrm{H}, \mathrm{d})$, $7.34(4 \mathrm{H}, \mathrm{t}), 7.24(2 \mathrm{H}, \mathrm{t}), 7.10(2 \mathrm{H} \mathrm{s})$. The product was further confirmed by GC-MS.

Sequestration of Pd impurities from Heck Coupling Product

Trans-stilbene as a product from above $(308.7 \mathrm{mg})$ was dissolved in $15 \mathrm{~mL}$ of THF and added to $50 \mathrm{mg}$ of $\mathrm{Fe}_{\mathrm{x}} \mathrm{O}_{\mathrm{y}} @ \mathrm{Fe}$ nanoparticles under argon atmosphere. An additional 0.5 $\mathrm{mL}$ of $\mathrm{KOH}$ solution ( $\mathrm{pH} 10.3)$ was added. The mixture was stirred for 20 minutes and then allowed to stand for 2 minutes to allow the majority of the nanoparticles to collect on the magnetic stir bar. The solution was gravity filtered and the nanoparticles washed three times with THF. The filtrate solvent was removed in vaccuo yielding off white crystals (302.7 mg, 98\%). No additional products were observed by GC-MS.

Determination of Metal Concentrations in Heck Coupling Product

Organic products (ca. $115-125 \mathrm{mg}$ ) were placed in a sublimation flask and heated to 200 ${ }^{\circ} \mathrm{C}$ under dynamic vacuum. The residual dark solids remaining in the flask were dissolved in warm concentrated nitric acid and diluted with $18.2 \mathrm{M} \Omega \mathrm{cm}$ water in a $10.00 \mathrm{ml}$ volumetric flask. Metal concentrations were found with Quad-ICP-MS.

\section{Material Characterization}

Quadropole Inductively Coupled Plasma- Mass Spectroscopy (Quad ICP-MS) was performed on a Perkin Elmer Elan 6000 ICP-MS. Samples were acidified with nitric acid to $\mathrm{pH}<2$. The flow rate on the instrument was $1 \mathrm{ml} / \mathrm{min}$ and dual detector mode was employed. A blank was subtracted after internal standard correction and the values reported are an average of three readings ( 35 sweeps per reading).

Gas Chromatography- Mass Spectroscopy (GCMS) was performed on a Waters 7070E GC-MS using electron ionization. $1 \mu \mathrm{L}$ of a dichloromethane solution of the product was injected into a Phenomenex ZB-5, 30m x $0.25 \mathrm{~mm}$ column with a $0.35 \mu \mathrm{m}$ film. The carrier gas was helium at $1 \mathrm{~mL} / \mathrm{min}$.. The injection port was at $275^{\circ} \mathrm{C}$ and a linear temperature profile $\left(50{ }^{\circ} \mathrm{C}-300^{\circ} \mathrm{C}\right.$ at $10{ }^{\circ} \mathrm{C}$ / minute $)$ was employed.

X-Ray Photoelectron Spectrosopy (XPS) was performed on and AXIS-165 XPS 
spectrometer from Kratos Analytical. The source was monochromatic Al K $\alpha$ X-rays at a power of $210 \mathrm{~W}$. The analyzer was perpendicular to the surface. Base pressure in the analytical chamber was $10^{-6}-10^{-7} \mathrm{~Pa}$. The area of the sample analyzed was $400 \times 700$ microns, with the analyzer normal to the surface. The pass energy for the survey spectra and the high-resolution spectra were $160 \mathrm{eV}$ and $20 \mathrm{eV}$ respectively. The instrument resolution is $0.4 \mathrm{eV}$. Samples were pressed in to carbon tape and spectra were calibrated to the $\mathrm{C} 1 \mathrm{~s}$ peak at $284.8 \mathrm{eV}$.

Transmission electron microscopy samples were prepared by suspending particles in THF and dropcoating the solution on carbon coated, 200 mesh $\mathrm{Cu}$ grid (SPI Supplies). Samples were evaluated using a JOEL 2010 Transmission Electron Microscope (TEM) at $200 \mathrm{keV}$ accelerating voltage and $\mathrm{LaB}_{6}$ filament. This instrument was also fitted with Energy Dispersive X-Ray (EDS) detector for elemental analysis.

(1) Lindsay, R. O.; Allen, C. F. H. Org. Synth. Coll. Col. 1955, 3, 710.

(2) Sun, Y. P.; Li, X. Q.; Cao, J. S.; Zhang, W. X.; Wang, H. P. Adv. Colloid Interface Sci. 2006, 120, 47-56.

(3) Li, X. Q.; Zhang, W. X. Langmuir 2006, 22, 4638-4642.

(4) Rostovtsev, V. V.; Green, L. G.; Fokin, V. V.; Sharpless, K. B. Angew. Chem. Int. Ed. 2002, 41, $2596-2599$.

(5) Cui, X.; Li, Z.; Tao, C. Z.; Xu, Y.; Li, J.; Liu, L.; Guo, Q. X. Org. Lett. 2006, 8, 2467-2470. 


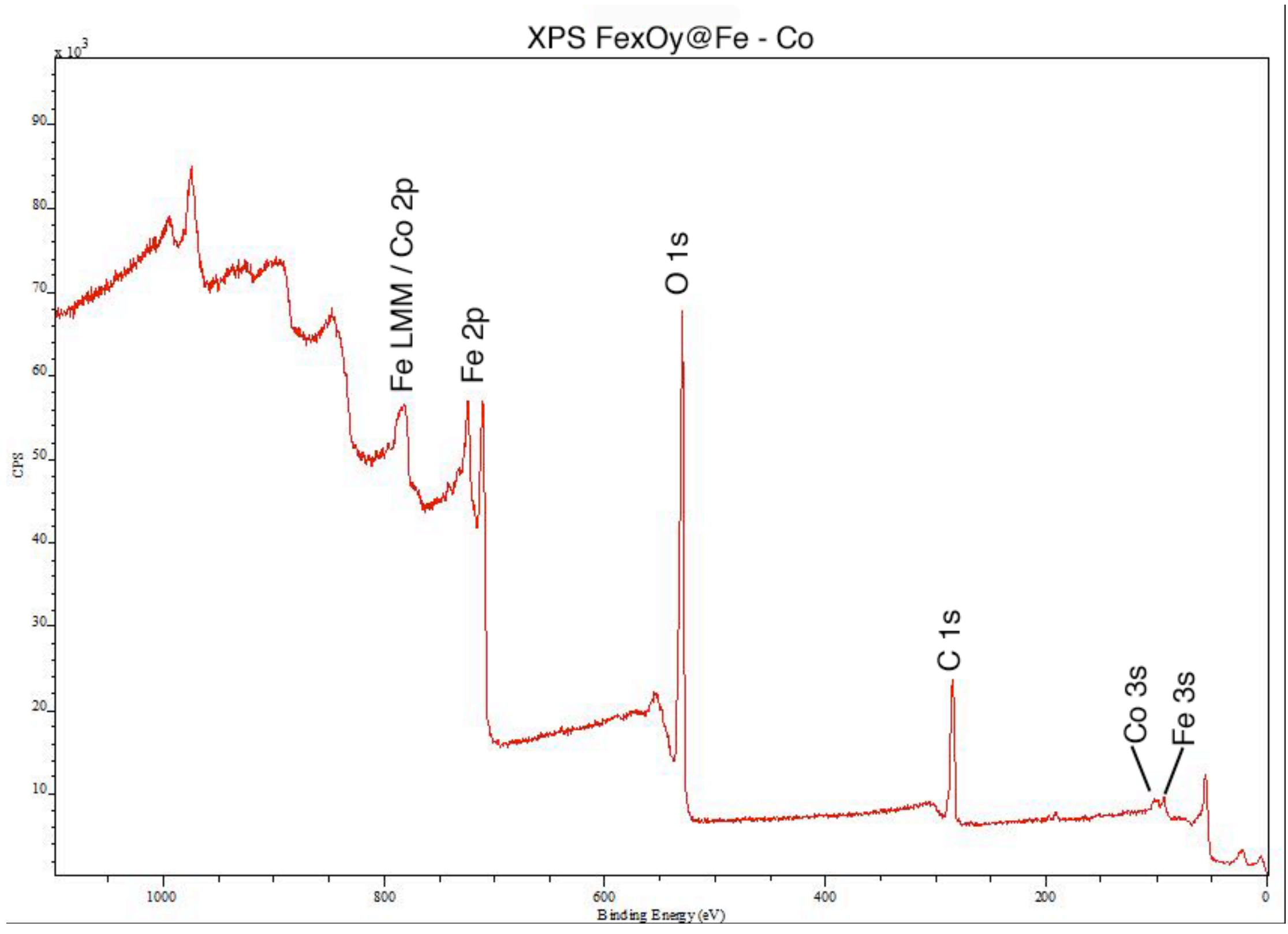




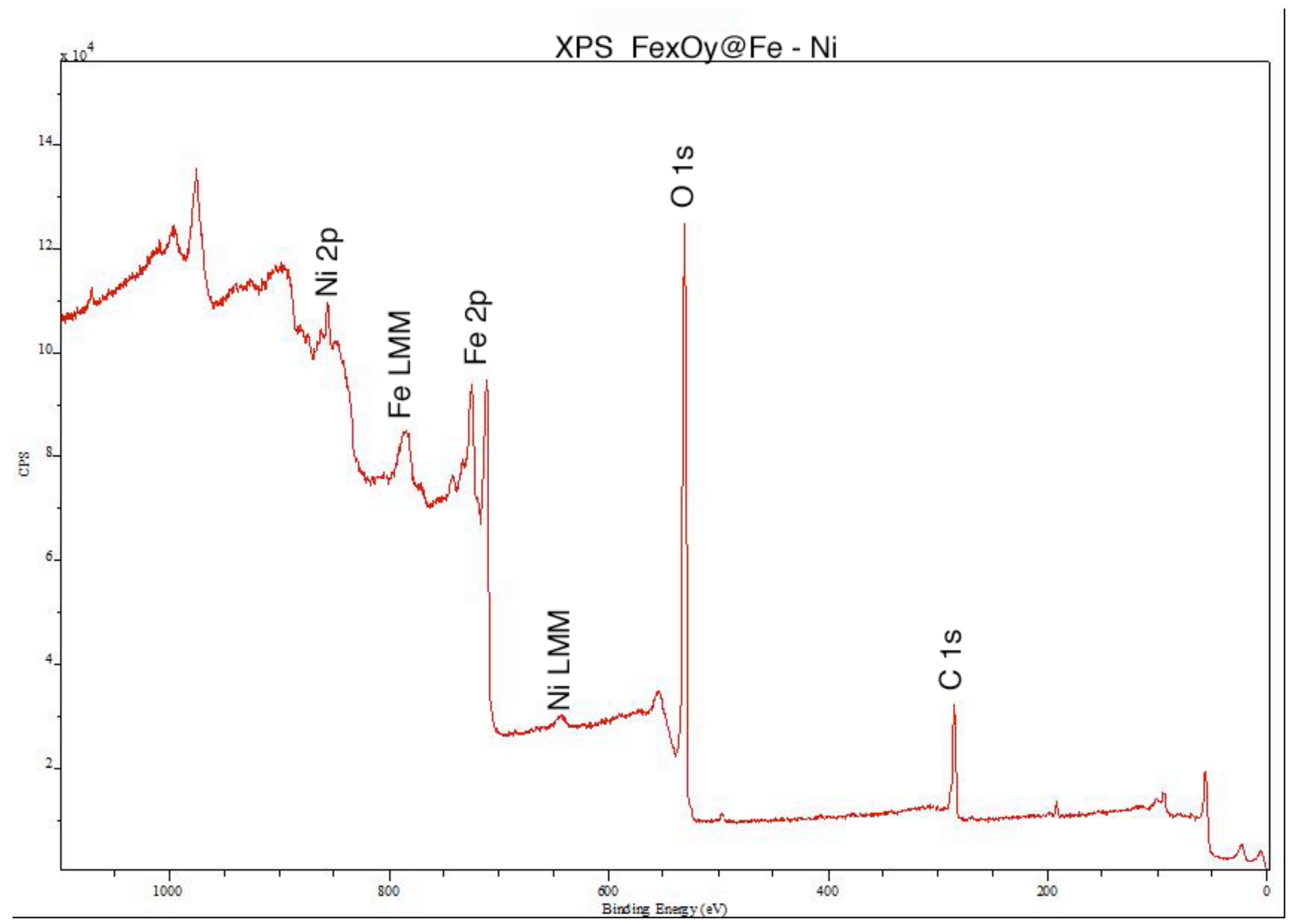




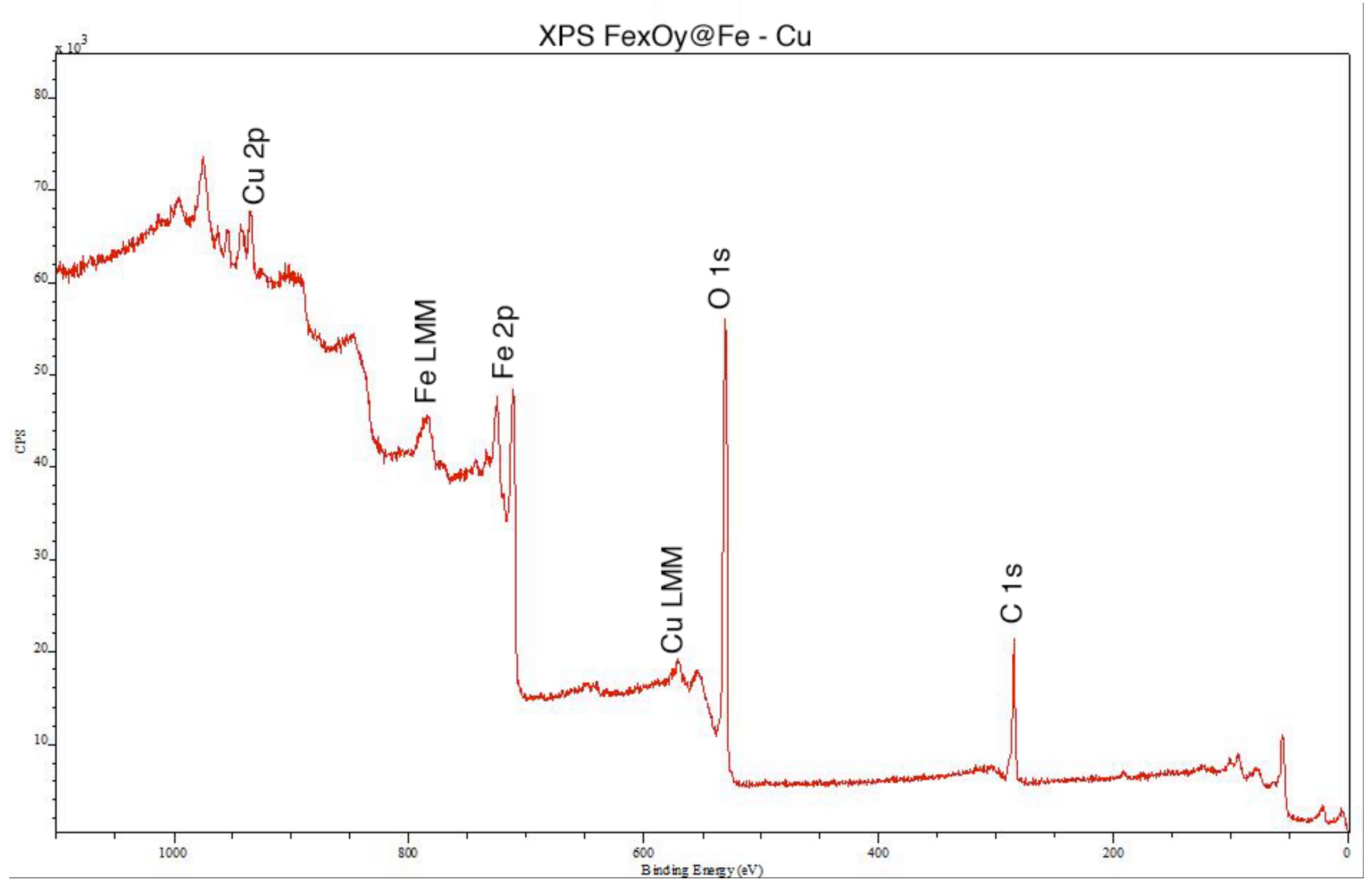




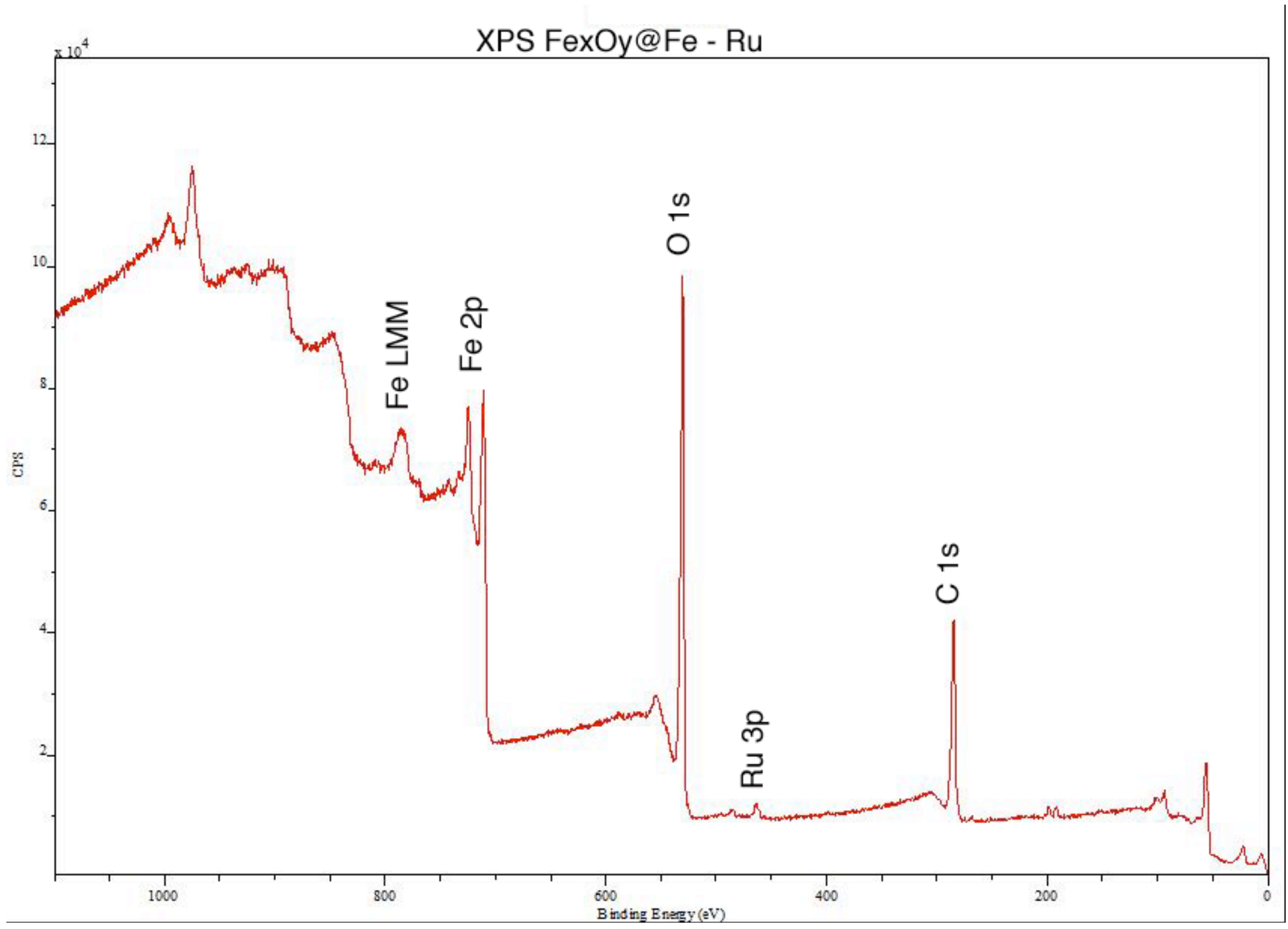




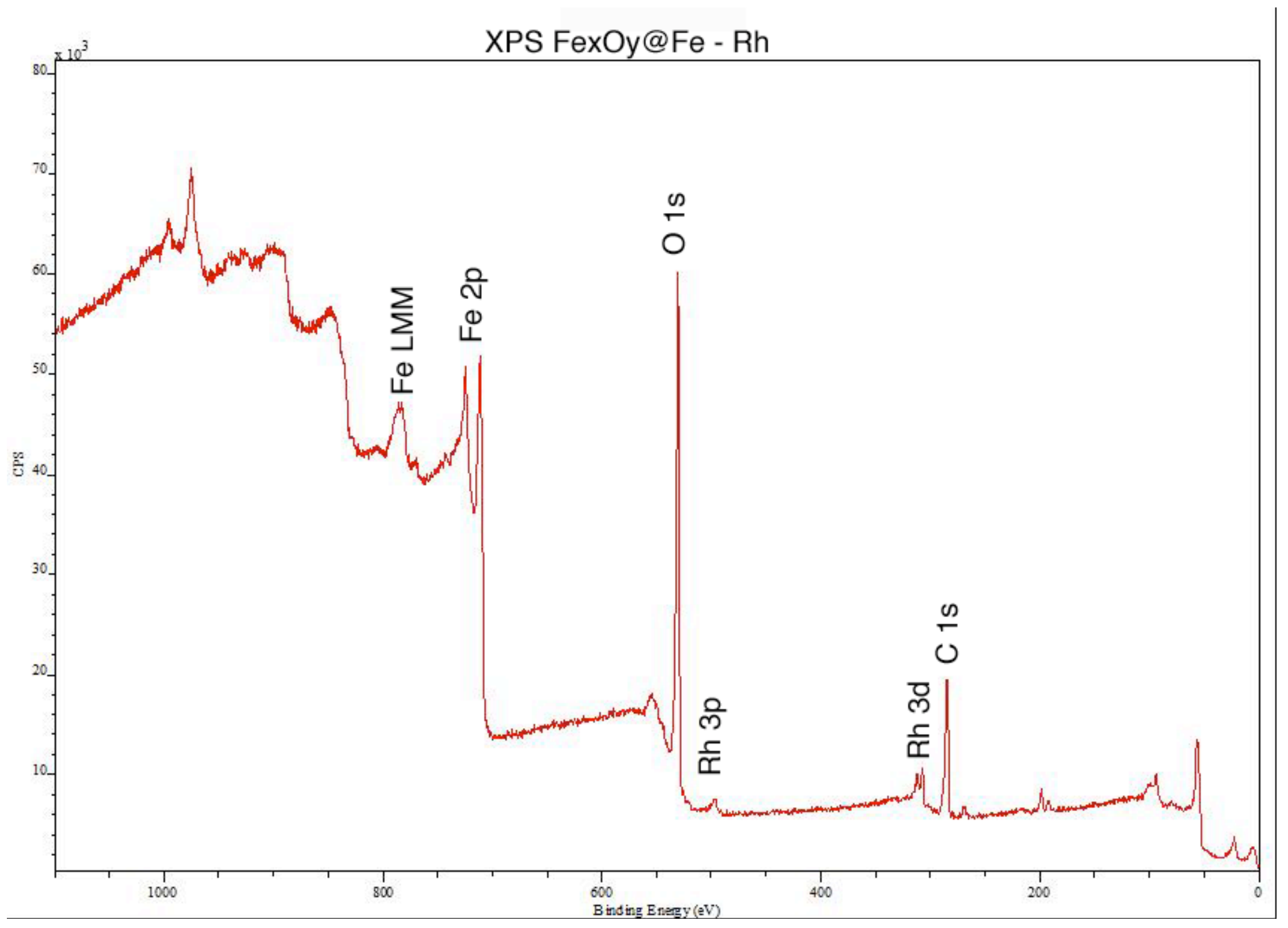




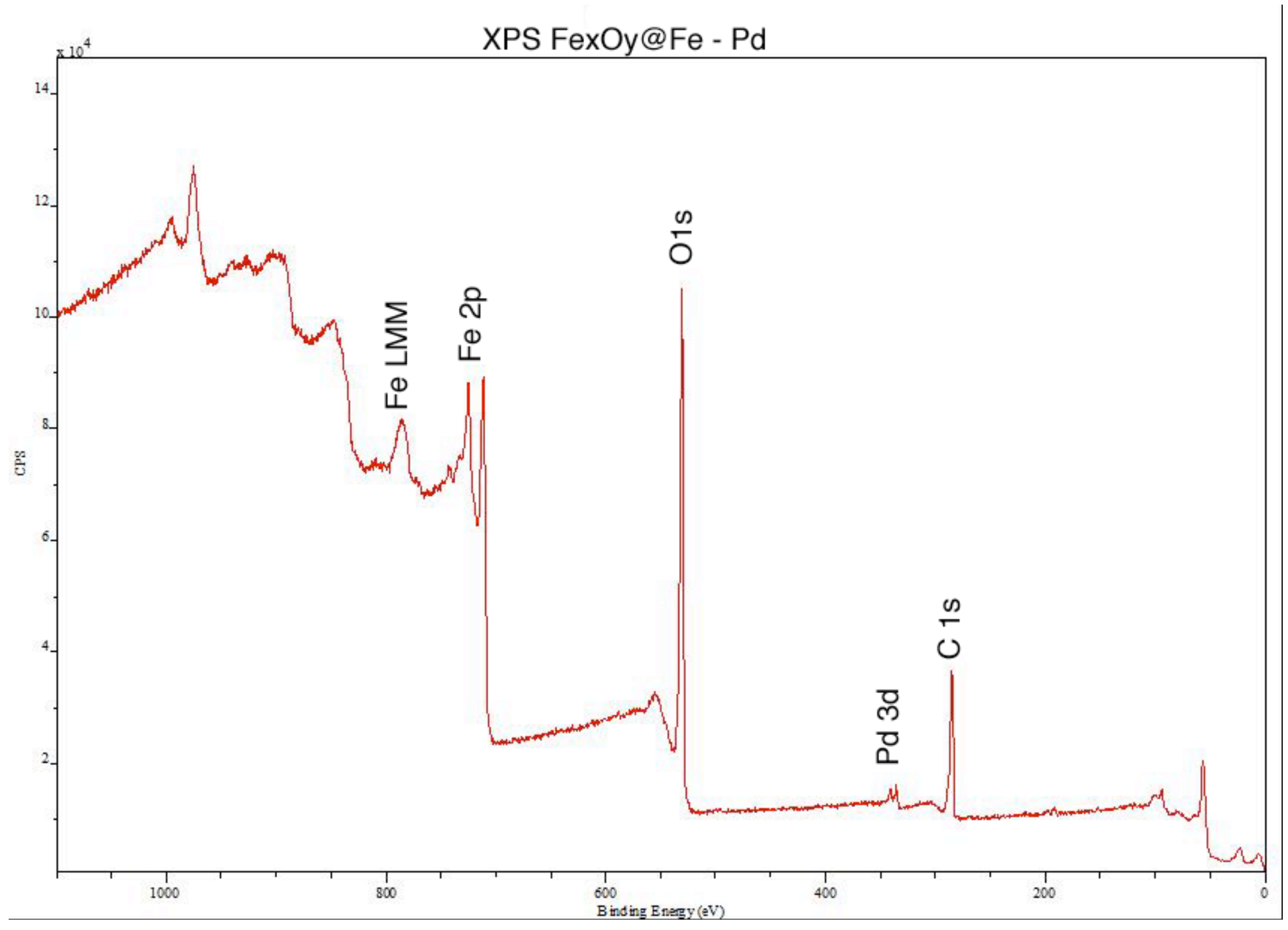




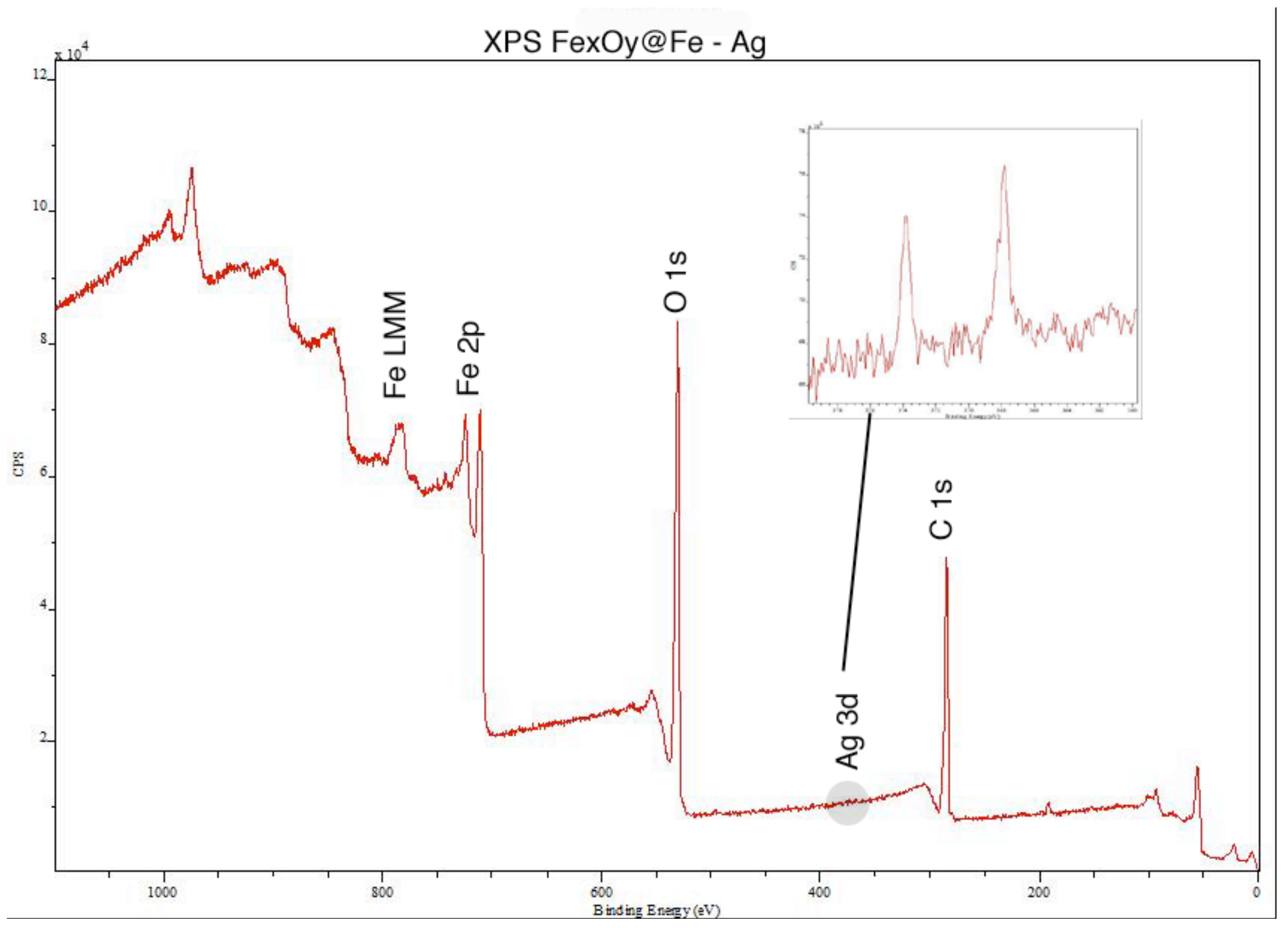




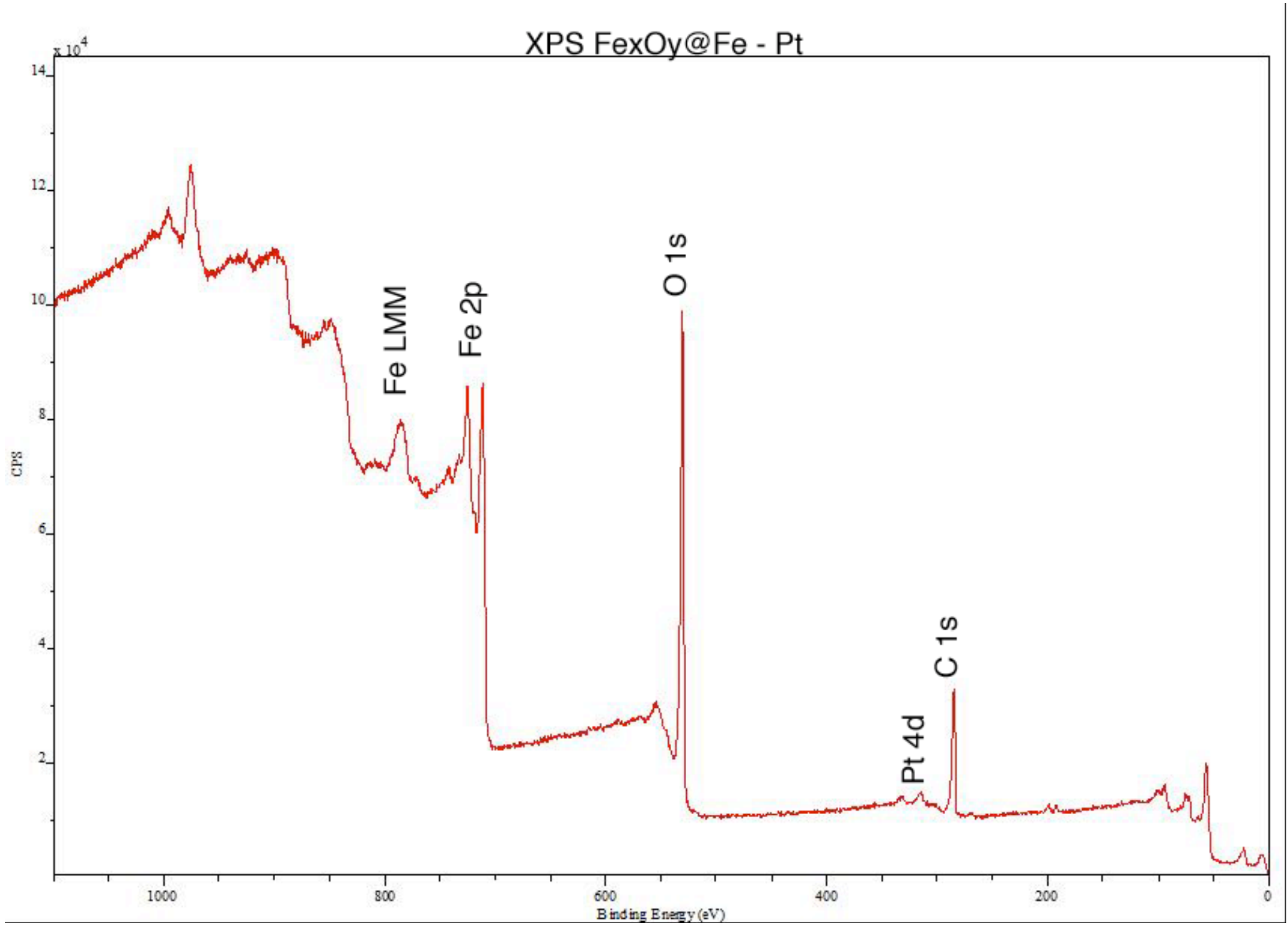

